\title{
Filosofia africana da educação: por uma cartografia da encruzilhada*
}

\author{
Filosofía africana de la educación: por una \\ cartografía de la encrucijada \\ African philosophy of education: for a cartography \\ of the crossroad
}

[Artículos del dossier]

Luis Carlos Ferreira dos Santos**

Fecha de entrega: 31 de julio de 2021

Fecha de evaluación: 15 de diciembre de 2021

Fecha de aprobación: 17 de diciembre de 2021

Citar como:

Santos, L.C.F. dos (2022). Filosofia africana da educação: por uma cartografia da encruzilhada. Cuadernos de Filosofía Latinoamericana, 43(126).

https://doi.org/10.15332/25005375.7511

(c) (i) (5) ()

\section{Resumo}

O texto apresenta uma filosofia africana da educação a partir da cartografia da encruzilhada das filosofias africanas. O tímido diálogo das filosofias a partir das experiências africanas na filosofia da educação brasileira se evidencia no combate ao negro africano no projeto político do Brasil. Portanto, problematiza o enclausuramento epistemológico com base na cartografia da encruzilhada na

\footnotetext{
* O artigo é resultado da pesquisa de mestrado que teve como título "Justiça como ancestralidade: em torno de uma filosofia da educação", desenvolvida na Faculdade de Educação, da Universidade Federal da Bahia, Brasil. O trabalho teve a orientação da professora Teresinha Fróes Burnham e coorientação do professor Eduardo Oliveira.

** Professor da Universidade Estadual de Feira de Santana, Brasil (UEFS). Doutor em Difusão do Conhecimento pela Universidade Federal da Bahia, Brasil (UFBA). Mestre em Educação pela UFBA. Graduado em Filosofia pela UFBA; Membro da Rede Africanidades da UFBA. Membro do Núcleo de Estudos Afro-Brasileiros e Indígenas (UEFS). Correio eletrônico: Icfsantos@uefs.br; ORCID: https://orcid.org/0000-0003-0514-5324
} 
crítica e na superação do semiocídio cultural e do epistemicídio, o que aponta a uma descolonização no sentido do educar.

Palavras-chave: filosofia africana, filosofia da educação brasileira, cartografia da encruzilhada.

\section{Resumen}

El texto presenta una filosofía africana de la educación desde la cartografía de la encrucijada de las filosofías africanas. El tímido diálogo de las filosofías desde las vivencias africanas en la filosofía de la educación brasileña se evidencia en el combate al negro africano en el proyecto político de Brasil. Por lo tanto, problematiza el enclausuramiento epistemológico desde la cartografía de la encrucijada en la crítica y la superación del semiocidio cultural y del epistemicidio, lo que apunta a una descolonización en el sentido del educar.

Palabras clave: filosofía africana, filosofía de la educación brasileña, cartografía de la encrucijada.

\section{Abstract}

The article presents an African philosophy of education from the cartography of the crossroad of African philosophies. The timid dialogue of the philosophies from the African experiences in the Brazilian philosophy of education is observed in the fight to the black African in the political project of Brazil. Therefore, it problematizes the epistemological cloistering from the cartography of the crossroad in the critique and the overcoming of cultural semiocide and epistemicide, which points to a decolonization in the sense of educating.

Keywords: African philosophy, Brazilian philosophy of education, cartography of the crossroad.

\section{Introdução}

Este artigo tem como ponto de partida problematizar a filosofia da educação brasileira, estabelecendo a paisagem do tremor e do barulhamento do diverso das filosofias africanas, no intuito de criticar as consequências para o educar do "epistemicídio" (Torres, 2010; Ramose, 2011; Carneiro, 2005) e do "semiocídio cultural" (Sodré, 1983).

Propõe-se investigar e apontar o modo como a cartografia na encruzilhada vem contribuindo ou poderá contribuir para a luta antirracista, a partir da filosofia africana da educação brasileira, e para o enfrentamento do epistemicídio e do semiocídio cultural. 
A perspectiva da filosofia africana da educação é um modo de filosofar a partir da dimensão mitopoética da experiência africana em "relação" com o "todo-mundo" (Glissant, 2011; 2009), na qual se alinham parte e todo, cultura e política, isto é, uma encruzilhada.

Nesse contexto, a filosofia africana da educação tem como finalidade potencializar uma educação antirracista, fixando como projeto político a crítica ao enclausuramento epistemológico e a busca pela ampliação da liberdade dos grupos historicamente negados do território brasileiro. Por isso, um pensamento que se relaciona com a educação antirracista, a partir do entendimento da filosofia africana, como práxis do educar. A ação base da filosofia da educação, tematizada com base na educação antirracista e na filosofia africana, ocorre a fim de promover justiça epistemológica e ampliar e manter as liberdades.

A discussão em torno de uma filosofia africana da educação estabelece algumas questões basilares para o seu agenciamento: a problematização do enclausuramento na epistemologia do educar e o grito do diverso. A partir do destaque feito por Nilma Lino Gomes, no texto "Diversidade étnico-racial e Educação no contexto brasileiro: algumas reflexões", pode-se perceber alguns desafios para o sucesso da educação antirracista, com destaque para a "necessidade de maior sistematização e divulgação do pensamento negro brasileiro nos meios acadêmicos e para profissionais da educação básica" (2007, p. 108). O diálogo filosófico de uma educação antirracista caracteriza-se como uma das questões-chave que este artigo enfatiza no debate da filosofia africana da educação, a qual é a tradução da disputa pela existência dos negros em território brasileiro. Portanto, tanto o epistemicídio quanto o semiocídio cultural revelam o fundamento da ausência e o aniquilamento físico e simbólico dos afrodescendentes.

O epistemicídio e o semiocídio cultural são produções da negação das construções de outras paisagens, sujeitos e contextos não lidos pela lente da transparência do eurocentrismo e dos Estados Unidos. O racismo epistemológico e a morte simbólica do diverso evidenciam a negação de saberes e conhecimentos, bem como o combate aos símbolos culturais como não lugar de construção de conhecimento e permanência dos africanos e latino-americanos. É um combate ontológico ao pertencimento e uma expressão do epistemicídio (Torres, 2010; Ramose, 2011; Carneiro, 2005) e do semiocídio cultural (Sodré, 1983).

O imaginário racista brasileiro traduz duas características que dão forma e conteúdo à justificativa do racismo epistemológico e da morte simbólica, apenas 
uma origem e um território cultural para o filosofar. A totalidade arbitrária aniquila a alteridade e se torna um dos fundamentos da injustiça.

O objetivo em filosofar desde e com saberes, conhecimentos e símbolos presentes na paisagem filosófica africana tem a finalidade de transgredir a armadilha do etnocentrismo epistemológico europeu moderno e de convocar para o apetite diverso do mundo.

Nesse contexto, este artigo tem como finalidade problematizar o combate ao enclausuramento epistemológico e ao monolinguismo cultural na área da filosofia da educação brasileira. Para isso, estabelece o diálogo com a filosofia africana, no sentido de fortalecer o enfrentamento do racismo, atualizado pela "poética do genocídio" (Santos, 2019), e fortalece o debate em torno da descolonização epistemológica.

O enfrentamento do racismo epistêmico e do semiocídio cultural objetiva problematizar e fortalecer a discussão da filosofia da educação brasileira, na perspectiva da filosofia africana, buscando a ampliação e manutenção das liberdades, na crítica ao racismo epistemológico e na amplificação do diverso na epistemologia do educar.

A construção filosófica da educação em diálogo com a perspectiva da identidade (totalitária) produz a ausência de outras cosmovisões na construção de conhecimento. Por isso, trava-se um diálogo entre a filosofia da educação e a cultura africana brasileira, de modo que "transborde as fronteiras do Si-Mesmo para encontrar a Alteridade" (Oliveira, 2006, p. 160). Isto é, partindo de sua singularidade, mas fundamentado em relações filosóficas, uma experiência de pensamento que institui os encontros entre a cultura e a política.

\section{Filosofia africana no desvio do semiocídio e do epistemicídio}

Muniz Sodré (1988) apresenta um conceito de cultura produzido sob a experiência dos afrodescendentes no Brasil. Segundo o autor, a palavra "cultura" é um campo muito explicativo do semiocídio. Este é entendido como o genocídio cultural cometido pela mentalidade "colonialidade-modernidade", que colonizou o continente africano e americano. Para escapar do semiocídio, Sodré (1988) dialoga com os conceitos de sentido e representação, bem como defende a ideia de que o entendimento de trabalhar com a categoria do sentido na interpretação do real tem como objetivo retirar o entendimento da significação, destruir, enquanto valores de representação, escapar da compreensão absoluta da identidade. 
O sentido fundamenta a diferença, enquanto a representação potencializa o genocídio do universal. Para escapar do conceito de cultura de um sentido abstrato e idealista, a perspectiva de "arkhé" é defendida, mas Sodré (1988) faz uma ressalva, porque postular um "arkhé", um simbólico como vetores da apropriação do real (cultura), leva à questão de saber, se não está em jogo um conceito que faz da cultura uma essência separada do real histórico. Para Sodré, a cultura não é nenhum sistema, nenhuma estrutura, mas o sedutor vazio que nos indetermina.

O conceito de cultura como um sedutor que indetermina é apresentado a partir do terreiro de candomblé, que é entendido como uma continuidade africana no Brasil e um impulso de resistência à ideologia dominante. O terreiro é a "arkhé" negra, de acordo com Sodré, pois, a partir da paisagem africana no Brasil, apresenta o conceito de cultura. Sodré (1988) apresenta no livro A verdade seduzida, conceitos desde o diálogo com o candomblé, a capoeira e a literatura de cordel, como segredo, luta, vazio, aparências, sedução, feitiço, mandinga, simbólico, diferença, aproximação, descontinuidade, heterogeneidade, corpo, mito negro, pós-moderno.

O epistemicídio e o semiocídio são traduzidos no fazer filosófico e cultural dos territórios africano e latino-americano, que se reinventaram na lógica injusta da colonialidade. A morte do diverso no campo epistemológico comete o aniquilamento cultural africano e ameríndio, negando o que é manifesto, o revelado: "o continente latino-americano é uma indústria indígena (em primeiro lugar!) e africana (a posteriori)" (Oliveira, 2007, p. 185).

A perspectiva dos projetos político-ideológicos presentes na mentalidade da colonialidade-modernidade e sua perpetuação na lógica neoliberal (Mbembe, 2017) evidenciam a subjugação do mundo (africano e latino-americano) e do humano (negros, mulheres, ameríndios). Portanto, é imprescindível a devida crítica ao projeto moderno-colonial filosófico. O eurocentrismo e a questão da dominação por meio da política e do conhecimento na filosofia contemporânea têm sido criticados.

As duas categorias, "epistemicídio" e "semiocídio cultural”, são traduções da parca reflexão acerca do projeto político que, historicamente, o pensamento comprometido com o aprisionamento e a servidão buscaram colocar a Europa em um lugar de destaque na epistemologia.

Torres (2010), trazendo para o debate a perspectiva da colonialidade, busca ultrapassar e combater o imperialismo colonial e colocar em crise o projeto da 
colonialidade. Existe um apagamento desse fato histórico em suas elaborações, tanto na ontologia quanto na ética, segundo Torres (2010).

Um dos pontos que Torres (2010) e os críticos do projeto da colonialidade abordam é a crítica ao projeto epistemológico, político e cultural eurocentrado. Autores "decoloniais", como o que acabo de citar, que buscam descolonizar a epistemologia, problematizam o colonialismo-racismo, partir da compreensão de que o enfrentamento do racismo deve ser pela via epistêmica. O racismo epistêmico tem como finalidade política o não reconhecimento do outro como humano. Aqueles fora da totalidade do humano não são apenas negados, mas combatidos. Segundo Torres (2010), “o racismo epistêmico descura a capacidade epistêmica de certos grupos de pessoas. Pode basear-se na metafísica ou na ontologia, mas os resultados acabam por ser os mesmos: evitar reconhecer os outros como seres inteiramente humanos (p. 405).

O racismo epistêmico e o aniquilamento simbólico africano problematizam a espacialidade unicultural na abordagem filosófica. Outros sujeitos antes "condenados da terra", agora dono de seu próprio movimento em sua terra e em terras alheias, mas sem esquecer que terra alheia não é morada. A relação dos efeitos da colonialidade na América Latina tem seus desdobramentos entre a política (poder), a epistemologia (saber) e a ontologia (ser). A diferença apontada por Torres (2010), para os filósofos ocidentais, é acerca da busca das raízes da Europa, não constituindo um mundo diverso, do ponto de vista epistêmico. Nessa perspectiva, Torres (2010) argumenta que estabelecer apenas a Europa como paisagem única não constitui um mundo diverso. Portanto, "no mundo, há muito para aprender com aqueles outros que a modernidade tornou invisíveis" (p. 437).

A negação das filosofias africanas é a tradução do combate aos africanos (no continente) e dos seus descendentes (nos arquipélagos espalhados pela diáspora) em se afirmar como ser humano. O racismo epistemológico é uma ação estrutural e sistemática aos africanos e aos seus descendentes. Nesse caso, as filosofias africanas são a tradução da luta de afirmação ontológica dos afrodescendentes. Ramose (2001) afirma que "os conquistadores da África durante as injustas guerras de colonização se arrogaram a autoridade de definir filosofia. Eles fizeram isso cometendo 'epistemicídio', ou seja, o assassinato das maneiras de conhecer e agir dos povos africanos conquistados" (pp. 5-6). A luta pela legitimidade e a dúvida da existência da filosofia africana é uma metáfora da afirmação do ser

${ }^{1}$ Alusão ao livro Os condenados da terra, de Frantz Fanon (2010). 
humano africano. A existência do ser humano está implicada com a existência de sua experiência. A experiência humana é o que assegura a sabedoria, ou seja, é o chão. Entretanto, o pensamento moderno europeu, fundamentado na religião cristã (fé) e no conhecimento (razão), questionou "o estatuto ontológico de seres humanos africanos” (Ramose, 2011, p. 7). A partir dessa construção argumentativa, foi defendida com base no "ideologismo" de que a filosofia não existia na África, pelo fato de o projeto econômico, político e cultural ter retirado a sua população da categoria de seres humanos, a partir de um fundamento racial.

Os filósofos africanos e os da diáspora problematizaram a não legitimidade da filosofia, no intuito de buscar responder à pergunta "O que é a África no pensamento e na vida internacional de hoje?” (Ngoenha, 1994, p. 83). A reivindicação pela filosofia tinha como finalidade buscar justiça e liberdade para o continente.

O epistemicídio teve sua fundamentação através da razão e da fé, estabelecendo como objetivo a conquista do poder, através de um argumento pretensamente universal, fundamentado pelo giro da mesmidade e da totalização. Um outro argumento é a reivindicação da filosofia universal, sem ponto de partida.

Entretanto, na esteira da argumentação de Ramose (2011), a particularidade é um ponto de partida, mesmo quando a filosofia ocidental moderna busca uma filosofia sem cultura, etnia/raça, ancestralidades, ou seja, universal sem contexto, ainda assim, é uma perspectiva. Logo, a fundamentação do epistemicídio é contraditória, o ponto de partida é um paradigma.

À luz da chave de leitura do epistemicídio e do semiocídio, justifica-se a importância de filosofar e educar com a experiência das paisagens africanas recriadas no território brasileiro. A modernidade encobriu sujeitos africanos e ameríndios. A filosofia marcada pelo projeto epistemológico da linearidade, essência e homogeneidade é uma representação da monocromia e monologia.

\section{Cartografia da encruzilhada}

A cartografia da encruzilhada, no exercício de relacionar uma fronteira à outra, trazendo a necessidade de um olhar da multirreferencialidade, da complexidade e da transdisciplinaridade, diante dos problemas humanos e do mundo, defende uma diversidade de linguagens.

A cartografia da encruzilhada tem direção, mesmo que inverta a ideia do fio condutor linear e homogêneo. A paisagem da cartografia movimenta o trajeto da 
caminhada e o movimento dos redemoinhos na encruzilhada, retira da margem a imprevisibilidade e a errância como possibilidade de caminho do educar.

A cartografia, segundo Deleuze e Guattari (1995), procura o acompanhamento dos processos, potencializando as suas conexões. A lógica da estrutura é descartada, posto que a cartografia não pode ser justificada por hierarquias de conceitos e sentidos. Nela, a cartografia, é possível a multiplicidade de entradas. A construção é o princípio do mapa, não a reprodução decalcada. Segundo Deleuze e Guattari (1995):

diferentemente das árvores ou de suas raízes, o rizoma conecta um ponto qualquer com outro ponto qualquer e cada um de seus traços não remete necessariamente a traços de mesma natureza; ele põe em jogo regimes de signos muitos diferentes, inclusive estados de nãos signos. (p. 43)

A cartografia da encruzilhada, em diálogo com a imagem deleuziana, estabelece a compreensão da tentativa de entender a multiplicidade de lógicas de lugares que compõem o universo epistemológico, ético e estético das filosofias africanas, afrodescendentes e da libertação latino-americana.

Uma outra característica presente é a multiplicidade. A linha de contato entre as várias perspectivas filosóficas africanas e afrodescendentes coloca a ideia de uma origem do pensamento filosófico em crise, posto que a ruptura explode a totalidade absoluta e transforma a multiplicidade como senha para interpretar e produzir sentidos no território de interesse. A imagem do fio explode, pois enforcou-se no redemoinho da cartografia da encruzilhada.

A cartografia possibilita a problematização, questões como "quem é o sujeito do discurso?", "qual o contexto do discurso?" e "qual o sentido da funcionalidade do discurso?". Os questionamentos, invariavelmente, colocam a ruptura como uma produção necessária e suficiente do fazer filosófico nos espaços ontológicos e epistemológicos negados. A ruptura no sentido de Deleuze e Guattari (1992; 1995; 1996) é do mesmo entendimento das linhas de fuga, no sentido de desterritorialização. $O$ pensamento nesse processo de ruptura foge do sistema, quebra as raízes de forma rizomática. As rupturas na cartografia da encruzilhada servem como quebra de modelos (neo)coloniais e (neo)imperialistas que trazem em suas faces o racismo e as dimensões variadas de violência.

A cartografia, em contraponto ao decalque, impõe a experimentação como regra e reprodução. Portanto, perde o lugar na criação do conhecimento. A reprodução constrói um inconsciente fechado sobre si mesmo, diferentemente do mapa. 
A cartografia tenta não cair na armadilha do entendimento do todo sem conexão com as partes, com compreensões totalitárias, fechadas, sem a possibilidade de mudanças. $\mathrm{O}$ que os mapas têm demonstrado é a abertura para a outra lente interpretativa a todo instante. E a abertura presente nos mapas possibilitam as conexões que provavelmente não se dariam sob um olhar linear fundamentado na homogeneidade. A cartografia trabalha com o que é desmontável, não mais com a irreversibilidade, mas com o reversível. As mudanças são necessárias para as zonas que não dialogam e se encontram nas linhas e conectores das cartografias.

O decalque (a reprodução) na cartografia apresenta os conflitos, as zonas de tensões estruturantes do mapa. Os decalques e os mapas produzem sentidos dessemelhantes. Enquanto os decalques precisam se referir aos mapas, o inverso não é verdadeiro. Segundo Deleuze e Guattari (1995):

O mapa não reproduz um inconsciente fechado sobre ele mesmo, ele o constrói. Ele contribui para a conexão dos campos, para o desbloqueio dos corpos sem órgãos, para a sua abertura máxima sobre um plano de consistência. Ela faz parte do rizoma. O mapa é aberto, é conectável em todas as suas dimensões, desmontável, reversível, suscetível de receber modificações constantemente. Ele pode ser rasgado, revertido, adaptar-se a montagens de qualquer natureza, ser preparado por um indivíduo, um grupo, uma formação social. (p. 30)

O decalque constrói um discurso estático, com imagens sem movimento. As cartografias trabalham com a imagem em movimento. É a própria linguagem do cinema que constrói sentidos com as fotos em movimento. A cartografia dialoga de maneira relacional, a partir do seu contexto. Pode-se dizer que o lugar da cartografia pode ser o rizoma, a multiplicidade.

Uma das imagens que podem ser utilizadas neste artigo é o suicídio de Ariadne no redemoinho da Lama de Nanã. Segundo Santos (2014), “Ariadne enforcou-se no redemoinho da lama de Nanã. O símbolo da lama é a transmutação dessa produção de subjetividade suicida totalitária, com caminhos unívocos, para um movimento do redemoinho. [...] A lama é o renascimento, inclusive de Ariadne" (p. 27).

A filosofia contemporânea tem sistematicamente produzido uma crítica ao pensamento fundamentado pela mesmidade, problematizando que tais horizontes recaem nas tragédias, como do totalitarismo nazista e do escravismo. Utiliza-se como metáfora desse fracasso o suicídio de Ariadne. Foucault (2013), em referência ao livro Diferença e repetição, de Gilles Deleuze, escreveu "Ariadne enforcou-se", significando a morte do projeto moderno da linearidade, da 
representação e da homogeneidade. Ariadne realmente enforcou-se, mas, nessa paisagem, foi no redemoinho da Lama de Nanã. O redemoinho é uma referência a Exu, como da encruzilhada, o lugar da multiplicidade e movimentos intensos e constantes. E Nanã é uma divindade da religião da matiz africana. Segundo Luz (2003),

Nanã e seus dois filhos míticos, Obaluaiê e Oxumaré, são orixás que regem os princípios do renascimento, do poder e mistérios interior da terra. O culto desses orixás se estende por vastas regiões na África, e no ex-Dahomé, atual Benin, Nanã é sincretizada com $M a w u$, Ser Supremo, princípio feminino que criou todos os voduns do panteon Fon e Ewe, juntamente com Lisa, Ser supremo, princípio masculino. (p. 68)

O suicídio de Ariadne é o enforcamento no projeto político-epistemológico do Ocidente (linear, homogêneo e totalitário), sendo tomado na diversidade do redemoinho, que traz a mesma perspectiva da encruzilhada, a qual liga todos os pontos, é o encontro, mas com os limites das especificidades, das diferenças. "A fronteira denota o limite de um território e outro; a encruzilhada é o lugar mesmo em que se cruzam as fronteiras. Aqui, mesmo os limites se cruzam e confundemse uns nos outros" (Oliveira, 2007, p. 116). A lama oferece unidade à diversidade, sendo ela o princípio primordial da criação do homem, no mito da tradição ioruba. A imagem de Ariadne enforcando-se nos fios movimentados pelo redemoinho da Lama de Nanã é a significação das viradas epistemológicas presentes na cartografia da encruzilhada.

Na paisagem da cartografia da encruzilhada, Ariadne acabou por se suicidar na lama de Nanã depois da vertigem no redemoinho. Esta é a imagem que traduz a virada epistemológica da filosofia africana da educação: a recriação dos outros corpos no espaço-tempo. Portanto, o corpo diverso explodiu o espaço-tempo linear e homogêneo.

A cartografia da encruzilhada produz um efeito acerca do fenômeno analisado de uma fragmentação da totalidade, mas enfatizando as partes, que não perdem o sentido do todo no sistema. É a ênfase nas partes, mas sem perder a importância da dimensão do todo. É o todo e as partes conectados. 
Suely Rolnik2 (1989) afirma que o cartógrafo antes de tudo é um antropófago. Inspiro-me nela para afirmar: o cartógrafo das filosofias africanas é um sujeito coletivo da encruzilhada. A cartografia nessa paisagem leva para caminhos múltiplos. A tecnologia da encruzilhada explode o caminho unívoco como possibilidade centrada, a multiplicidade de caminhos é um paradigma. Os caminhos são múltiplos, por isso também são os conflitos, as dobras e as possíveis conclusões.

O olhar da encruzilhada na cartografia constrói as intersecções necessárias para produzirem sentidos entre si, pois esta é uma metodologia instigante, porque possibilita a travessia de uma perspectiva política, epistemológica e ética-estética, diferentes, mas que necessariamente dialogam, sem perder suas especificidades e evidenciando seus projetos políticos. E a lente interpretativa da encruzilhada possibilita o encontro sem as perdas das teorias e das perspectivas.

A cartografia tem como característica a antigenealogia (Deleuze e Guattari, 1995, p. 29). Os caminhos conectam-se, mas não determinam a origem. É o pensamento imagem da encruzilhada. A origem na encruzilhada é uma escolha. Ela busca fundamentação em constante movimento.

A perspectiva genealógica de uma origem única explode as possibilidades de desmontagens e montagens dos caminhos e imagens. A cartografia, na perspectiva da encruzilhada, traz a funcionalidade da discussão do pensamento contemporâneo em sua tradição epistêmica.

A encruzilhada como apresentada escapa da compreensão apenas do uno e do múltiplo. Ela busca fugir do perigo de apenas compreender a unidade, visto que vários caminhos não somente se entrecruzam, mas também fogem do entendimento de afirmar o múltiplo de cair em uma generalização arbitrária. A encruzilhada cruza os caminhos e encontra a multiplicidade da filosofia contemporânea.

A partir da cartografia da encruzilhada, da filosofia africana, perceberam-se grandes eixos que aglutinam as perspectivas enredadas na construção

\footnotetext{
2 Suely Rolnik traduziu algumas obras de Deleuze e Guattari, a exemplo de Mil platôs volume 1, e trabalhou no desenvolvimento da discussão acerca da cartografia. Entre suas publicações estão, Micropolítica: cartografias do desejo, produzido com Guattari, e Cartografia sentimental: transformações contemporâneas do desejo. Rolnik dialoga com o trabalho cartográfico a partir das atividades do esquizoanalista, do analista do desejo, do psicólogo social e do micropolítico. Cada uma dessas cartografias citadas terá um cartógrafo, realizará cartografia na medida em que criar sentidos, não revelá-los.
} 
argumentativa do texto: descolonização epistemológica, desvio da mentalidade racista e apetite pelo diverso do mundo.

\section{Filosofia africana da educação}

Uns dos temas recorrentes nas produções das filosofias africanas se dá em torno da defesa da descolonização do pensamento, da busca pela liberdade, da compreensão do mundo e do humano na crítica ao modelo colonial-moderno, na defesa do diverso epistemológico e do modo de vida.

A defesa e a legitimidade das filosofias africanas surgem como uma crítica ao não reconhecimento dos africanos como humanos. As filosofias africanas têm historicamente problematizado as condições e a urgência da convivência. Para isso, coloca na agenda alguns temas: crítica ao capitalismo, problematização do neoliberalismo, da escravidão e do racismo, estabelecimento da urgência de repensar os modelos econômicos da relação homem-natureza, a luta civil, a independência política dos países africanos. Um outro ponto que perpassa as reflexões travadas por Paulin Hountondji (1983), V. Y. Mudimbe (2013), Mogobe Ramose (2011), Severino Elias Ngoenha (1994; 2014), é a utilização dos recursos africanos em prol do desenvolvimento do próprio continente. Segundo Ngoenha (1994):

A prioridade africana é hoje lutar pela sobrevivência e contra a sua marginalização internacional. Isto pressupõe uma vitória no sector da produtividade e de uma relação positiva com o mercado internacional. Porém, estes objetivos não podem ser alcançados no quadro das políticas de ajustamento estrutural. O conflito com o mercado internacional não pode ter uma sentença em favor do continente se ele continua a ser negociado no quadro dos programas de ajustamento estrutural, a partir dos postulados definidos e impostos pela Banca Mundial e pelo fundo monetário internacional. (p. 68)

As filosofias africanas, por meio da cartografia, evidenciam a importância de debater a retirada dos africanos da categoria da humanidade fundamentada pelo racismo. Essa questão é de muita ênfase, e isso é o que torna a perspectiva de filosofar, apresentada pela paisagem africana, marcadamente um projeto por um outro humanismo. A restituição por uma outra justiça social e a ampliação das liberdades são paradigmas que atravessam os filósofos das paisagens africanas. A disputa pela liberdade é um elemento que tem muita força na construção argumentativa dos embates em torno dessa perspectiva. 
Na filosofia afro-americana, na personalidade negra, Du Bois e Blyden, à luz da leitura de Mudimbe (2013), por exemplo, problematizam a questão política, a partir de um ponto de vista racial. A questão racial é um problema filosófico imprescindível para se pensar uma filosofia da educação como prática de liberdade.

Em Blyden, a partir da leitura de Mudimbe (2013), é possível perceber a personalidade africana de um ponto de vista racial dos negros norte-americanos. $\mathrm{O}$ debate em torno da identidade, da história e da cultura é considerado em termos de raça, e esta perspectiva é compreendida como fundamental.

Segundo Mudimbe (2013), a filosofia política de Blyden trazia algumas características de muita importância para a disputa do enfrentamento do racismo, pois relativizou a superioridade das categorias, tais como cristão, civilizado e branco. O civilizado passou a ser uma iniciativa negra; o desenvolvimento da Libéria, por exemplo, seria construído pelo novo negro. Mas não era qualquer negro, já que os "nativos" eram considerados pagãos e os que sofreram o jugo do escravismo bárbaro. Nesse sentido, percebem-se os graus de hierarquias no pensamento de Blyden, que, mesmo fazendo uma crítica ao racismo antinegro, sucumbe na armadilha da superioridade religiosa. Ele compreendia como inferiores as pessoas não mulçumanas, mesmo defendendo que somente os negros teriam legitimidade em colonizar e reformar a África. Não era qualquer negro, mas as comunidades seriam organizadas à luz da liderança mulçumana.

A filosofia política de Blyden tinha como ponto de partida o entendimento que o africano foi uma vítima do etnocentrismo europeu, e esse ponto era uma máxima da sua luta contra a opressão da colonização.

As filosofias africanas trazem esse legado político, pois tem como ação base a disputa por processos de libertações, e o combate ao racismo é o que coloca em encruzilhada essas filosofias. O conceito de raça não aparece como um projeto epistemológico, mas um legado político a ser combatido e reconstruído. A reconstrução dá-se pelo fato de ser necessário construir identidades para memórias e corpos subjugados. A construção de paisagens para negros, ameríndios, quilombolas, grupos humanos que sofreram a consequência do racismo. Nessa perspectiva, é um enfrentamento do racismo pela perspectiva simbólica e material.

\section{Conclusão}

A filosofia africana da educação como aqui apresentada seria atinada: primeiro, a partir da sensibilidade; segundo, não busca o pensamento da transparência, porque 
assim não se restringiria apenas a um grupo, buscando escapar da lógica da arbitrariedade e do totalitarismo; terceiro, tem a imagem da encruzilhada, do redemoinho da lama de Nanã, sabendo de onde parte e em direção aos encontros de múltiplos caminhos, mas tendo destino. É um redemoinho intenso, complexo, mas com finalidade: afirmar a vida contra os projetos mortificadores.

A imagem da Lama de Nanã, que dá unidade, chegando ao sentido do "todomundo" (Glissant, 2009; 2011). E a unidade é uma constante derivação da multiplicidade.

Não se compreende a partir de um fio, de um corpo homogêneo, linear, mesmo labiríntico, mas dentro dos redemoinhos e das encruzilhadas. Isto não quer dizer que não tenha unidades, a lama é essa dimensão do "todo-mundo" (Glissant, 2009) ou do centro da encruzilhada. A lama, como esse lugar que possibilita uma unidade diferenciadora, é o elemento do princípio da existência. É o elemento simbólico da unidade e a diferença da humanidade.

A filosofia africana da educação na encruzilhada, com as derivas africanas e afrobrasileiras, tem como alvo a crítica ao fundamento do racismo (mesmidade e homogeneidade) e a superação dele (o diverso). Além disso, é uma paisagem de concretização de cidadania. E, diante do congelamento do mundo, com as suas formas variadas de violências, mobilizada pela "poética do genocídio" (Santos, 2019), faz-se necessária e urgente uma filosofia da educação que tenha como horizonte a vida.

O eco de uma filosofia africana da educação como cartografia da encruzilhada tem como destaque problematizar os corpos e memórias aniquilados pela modernidade-colonialidade. Portanto, ao ter a paisagem da experiência filosófica africana como paisagem do educar, tem como horizonte disputar projetos de cidadania. É o projeto de imaginação política de habitar um "outro humanismo" (Fanon, 2008), para estabelecer a vida em "relação" (Glissant, 2011) no "todomundo" (Glissant, 2009).

\section{Referências}

Carneiro, S. (2005). A construção do outro como não-ser como fundamento do ser. (tese de doutorado em Educação). Universidade de São Paulo.

Deleuze, G. e Guattari, F. (1992). O que é a filosofia? (B. Prado Jr. e A. A. Muñoz, trads.). Ed. 34.

Deleuze, G. e Guattari, F. (1995). Mil platôs: capitalismo e esquizofrenia (v. 1). Ed. 34.

Deleuze, G. e Guattari, F. (1996). Mil platôs: Capitalismo e esquizofrenia (v. 3). Ed. 34.

Fanon, F. (2005). Os condenados da terra. Editora UFJF. 
Fanon, F. (2008). Pele negra, máscara branca. EDUFB.

Foucault, M. (2013). Arqueologia das ciências e história dos sistemas de pensamento. Editora Forense.

Glissant, É. (2009). Philosophie de la relation: poésie en étendue. Éditions Gallimard.

Glissant, É. (2011). Poética da relação. Porto Editora.

Gomes, N. L. (2007). Diversidade étnico-racial e Educação no contexto brasileiro: algumas reflexões. Em Gomes, N. L. (org.), Um olhar além das fronteiras: educação e relações raciais (pp. 136-148). Autêntica.

Hountondji, P. (1983). African philosophy: Myth and reality. Indiana University Press.

Luz, M. A. de O. (2000). Agadá: dinâmica da civilização africano brasileira. (2ª ed.). EDUFBA.

Maldonado-Torres, N. (2010). A topologia do ser e a geopolítica do conhecimento. modernidade, império e colonialidade. Em: B. de S. Santos e M. P. Meneses (orgs.), Epistemologias do Sul (pp. 196-443). Cortez.

Mbembe, A. (2017). Políticas da inimizade. Antígona.

Mudimbe, V. Y. (2013). A ideia de África. Edições Pedago.

Ngoenha, E. (1994). O retorno do bom selvagem: uma perspectiva filosófica africana do problema ecológico. Edições Salasianas.

Ngoenha, E. (2014). Das independências às liberdades. Paulinas.

Oliveira, E. D. (2006). Cosmovisão africana no Brasil: elementos para uma filosofia Afrodescendente. ( $3^{\mathrm{a}} \mathrm{ed}$.). Editora Gráfica Popular.

Oliveira, E. D. (2007). Filosofia da ancestralidade: corpo e mito na filosofia da educação brasileira. Editora Gráfica Popular.

Ramose, M. B. (2011). Sobre a legitimidade e o estudo da filosofia africana. Ensaios Filosóficos, IV, 6-25. http://www.ensaiosfilosoficos.com.br/Artigos/Artigo4/RAMOSE_MB.pdf

Rolnik, S. (2011). Cartografia sentimental: transformações contemporâneas do desejo. Sulina; Editora da UFRGS.

Santos, L. C. F. dos. (2014). Justiça como ancestralidade: em torno de uma filosofia da educação no Brasil. (dissertação de mestrado em Educação). Universidade Federal da Bahia.

Santos, L. C. F. dos. (2019). O poder de matar e a recusa em morrer: filopoética afrodiaspórica como arquipélago de libertação. (tese de doutorado multi-institucional e multidisciplinar em Difusão do Conhecimento). Universidade Federal da Bahia.

Sodré, M. (1988). A verdade seduzida: por um conceito de cultura no Brasil. Livraria Francisco Alves Editora S. A. 